\title{
Efficient Operation of Heat Source using High-temperature Chilled Water in an Advanced Office Building
}

\author{
Yuya Suzuki ${ }^{1, *}$, Misa Imazu $^{1}$, Jun Shinoda ${ }^{1}$, Ryoya Furukawa $^{1}$, Yumiko Araki ${ }^{1}$, Shin-ichi Tanabe ${ }^{1}$, Kenji Fujino $^{2}$, Daisuke \\ Hatori $^{2}$, Nobuhiro Hirasuga ${ }^{2}$, Shun Kato ${ }^{2}$, Shiori Sasahara ${ }^{3}$, and Hiroki Iwata ${ }^{4}$ \\ ${ }^{1}$ Waseda University, 169-8555 Tokyo, Japan \\ ${ }^{2}$ Mitsubishi Jisho Sekkei Inc., 100-0005 Tokyo, Japan \\ ${ }^{3}$ Takasago Thermal Engineering Co., Ltd., 160-0022 Tokyo, Japan \\ ${ }^{4}$ TOYOX Co., Ltd., 130-0013 Tokyo, Japan
}

\begin{abstract}
In recent years, energy conservation has become a major focus in the industrial sector. Many office buildings in Japan achieve energy savings by introducing highly efficient equipment and systems, such as high-temperature cooling water $\left(14{ }^{\circ} \mathrm{C}\right)$, which increases heat source efficiency. However, such equipment requires adjustments to increase operational efficiency. In this case study, the efficiency of equipment using high-temperature cooling water was further improved through operation control optimization. The energy efficiency before and after the improvement was compared. The target building has chilled and hot water supplied to each floor from district heating and high-temperature chilled water supplied from cooling chillers on the rooftop. The energy consumption of two floors was evaluated: a subjective floor with equipment using high-temperature cooling water installed, and a common floor with a conventional system. After on-site verification, changes were made to the operation control of the cooling towers, condenser pumps, primary pumps, secondary pumps, and air handling units. As a result, the coefficient of performance of the water-cooled chiller and the whole system improved by 0.40 and 0.45 , respectively. The flow rate of the air conditioning equipment using high-temperature cooling water decreased while maintaining an equivalent amount of heat extraction. In conclusion, the efficiency of the equipment was further improved by operation control optimization.
\end{abstract}

\section{Introduction}

In recent years, energy conservation has become a major focus in various fields, including building engineering. Many tenant office buildings in Japan achieve energy savings by introducing highly efficient equipment, such as air conditioning using high-temperature chilled water $\left(14{ }^{\circ} \mathrm{C}\right)$. However, it is necessary to review and improve the operation control of such equipment after installation in order for it to operate efficiently. Therefore, energy consumption is evaluated by analyzing data from the building energy management system (BEMS) to identify further possibilities for improving energy savings. The aim of this study was to evaluate the efficiency of equipment using high-temperature cooling water in an office building before and after improvements in operation control.

\section{Methods}

\subsection{Description of the target office building}

\subsubsection{Heat source}

\footnotetext{
*Corresponding author: ysuzuki@tanabe.arch.waseda.ac.jp
}

The target office building adopts a central heat source system. Chilled and hot water are supplied to each floor from district heating and cooling (DHC), which is first distributed to the basement. In addition, the building has cooling chillers as its own heat source to generate hightemperature chilled water which installed on the rooftop [1][2]. The rooftop heat sources are illustrated in Fig. 1.

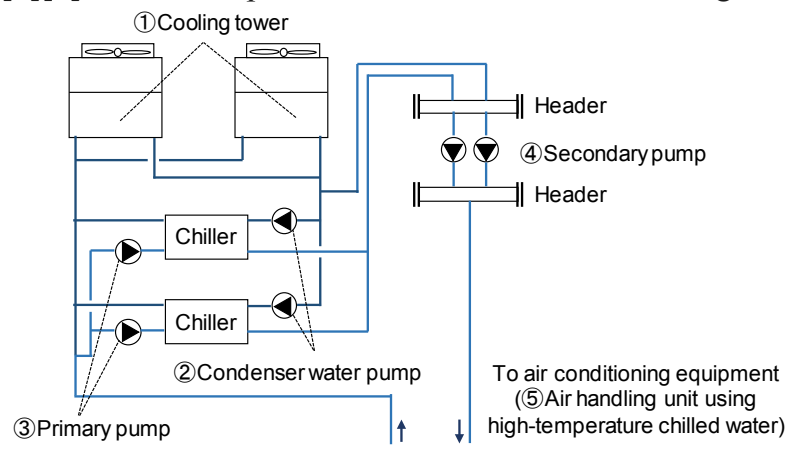

Fig. 1. System diagram of the heat source for high-temperature chilled water

\subsubsection{Air conditioning equipment}

The target floors in the office building are the subjective floor and the common floor, as illustrated in Fig. 2. The 
subjective floor is equipped with radiant air conditioning, desiccant air conditioning, air handling units, and desktop-type task air conditioning units. The common floor is equipped with an air handling unit system. The high-temperature cooling water generated from the rooftop heat source is supplied only to the air conditioning equipment in the subjective floor [1][2].

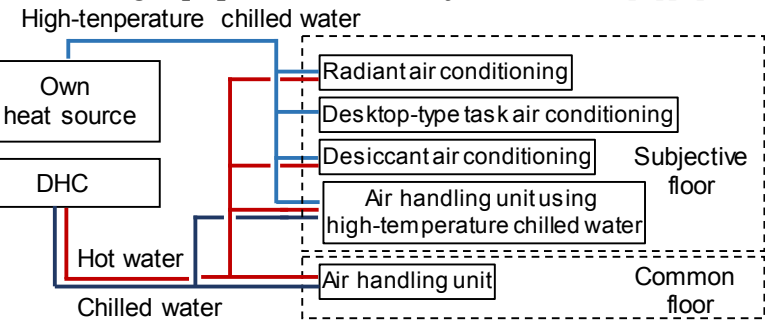

Fig. 2. Configuration diagram of air conditioning equipment of the subjective and common floors.

\subsection{Primary energy consumption}

Fig. 3. shows the primary energy consumption for air conditioning from 1 July to 30 September 2016. The primary consumption of the subjective and common floors was considerably reduced compared to the standard Japanese building, as calculated from an energy-saving index in Tokyo [3]. The common and subjective floor had an energy consumption $64 \%$ and $68 \%$ lower than the standard building, respectively. However, a large proportion of energy consumption in the subjective floor was attributed to the hightemperature chilled water equipment. With regard to chilled and hot water supplied from DHC, it is difficult to optimize the operation control because the water pressure and temperature are restricted. On the other hand, with regard to the high-temperature cooling equipment on the rooftop, the operation control may be adjusted freely. Therefore, the possibility of further improving the energy savings of the high-temperature cooling heat sources was studied.

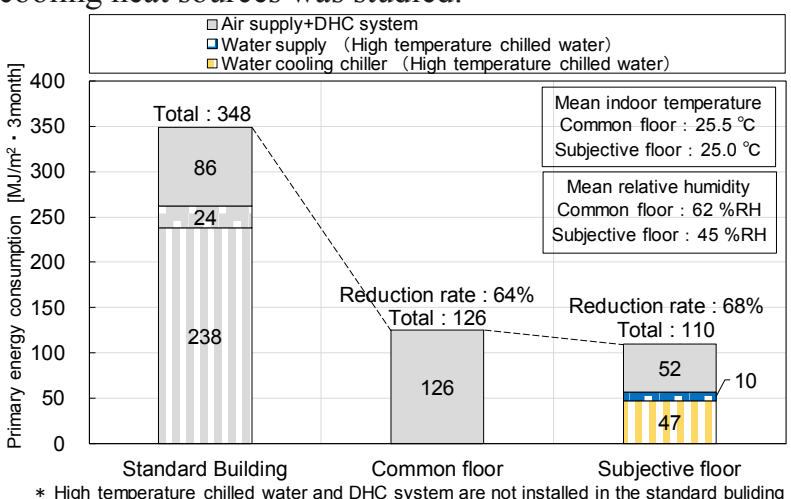

Fig. 3. Primary energy consumption in 2016

(1 July to 30 September), only for air conditioning

\subsection{Improvement in the operation control}

BEMS data was used to analyze the actual operating conditions of each component. As a result, it was revealed that there was room for improvement in the operating condition of each component. Therefore, changes were made to the operation control of each component in July 2017, as listed in Table 1. Changes were made to the heat source (cooling towers, condenser water pumps, primary pumps, and secondary pumps) and the air conditioning equipment (high-temperature cooling water air handling units).

Table. 1. Improvement in the operation control.

\begin{tabular}{l|l}
\hline \multicolumn{1}{c|}{ Subject } & \multicolumn{1}{c}{ Improvement } \\
\hline \hline (1) Cooling tower & $\begin{array}{l}\text { Control outlet temperature to follow } \\
\text { the outer air wet-bulb temperature }\end{array}$ \\
\hline (2) Condenser water pump & $\begin{array}{l}\text { Reduce the lower limit of inverter } \\
\text { to ensure temperature difference }\end{array}$ \\
\hline (3) Primary pump & $\begin{array}{l}\text { Reduce the lower limit of inverter } \\
\text { to ensure temperature difference }\end{array}$ \\
\hline (4) Secondary pump & Reduce the lower limit of delivery pressure \\
\hline (5) Air handling unit & $\begin{array}{l}\text { Adjust valve control to obtain constant } \\
\text { return water temperature }\end{array}$ \\
\hline
\end{tabular}

\subsubsection{Cooling tower}

Before the operation control improvement, the outlet temperature of the cooling tower was kept constant at $25^{\circ} \mathrm{C}$ for efficient operation of the water-cooled chillers. However, the capacity of the cooling tower exceeded its limit value owing to a change in the outside air wet-bulb temperature and a flow rate that was too high. Therefore, adjustments were made so that the outlet temperature of the cooling tower followed the outside air wet-bulb temperature to obtain a reasonable flow rate.

\subsubsection{Condenser water pump, primary pump, secondary pump}

On-site tests were conducted on the flow rate and delivery pressure of the chillers and pumps, and it was confirmed that the settings could be safely reduced. Therefore, the inverter frequency of the condenser pumps, primary pumps, and secondary pumps were adjusted to prevent excessive flow rate and reduce power usage. For the secondary pump, the end differential pressure was given as input value for the delivery pressure control settings through cascade control.

\subsubsection{Air handling unit}

Initially, no controls were set for the return water temperature of the air handling units for hightemperature cooling. Therefore, the control valve setting was altered so that the return water temperature achieved a constant value of $24{ }^{\circ} \mathrm{C}$. Thus, an inlet and outlet temperature difference of $10{ }^{\circ} \mathrm{C}$ was secured, preventing excess flow rate.

\section{Results and discussion}

The results of the operation control improvements are shown for both the heat source and the high-temperature cooling air handling units. The heat source includes cooling towers, cooling-water pumps, water-cooled chillers, and primary pumps. The period of BEMS data analysis was from 1 July to 30 September in both 2016 
and 2017. The target time of evaluation was set between 7:00 and 19:00 on work days.

\subsection{Heat source}

\subsubsection{Coefficient of performance and electric energy}

In order to compare the effect of the operation control, the coefficient of performance (COP) of the watercooled chillers and the entire system was calculated. The entire system here refers to the cooling towers, watercooled chillers, condenser water pumps, and primary pumps. Figs. 4. and 5. each show the occurrence time of the water-cooled chiller and entire system COP. Each bar of the histogram represents a COP within a range of 0.1 . The water-cooled chiller COP was calculated by dividing the amount of heat extraction from the chiller by the primary energy consumption of the chiller [4]. Likewise, the system COP was calculated by dividing the total heat extraction by the total primary energy consumption of each previously mentioned component. Each COP occurrence indicates an instantaneous value per hour during working hours. In addition, instantaneous values of zero were excluded from the calculation of the average COP.

In general, the water-cooled chiller COP values fell mostly within the range of 2.5 to 3.5 in both years. However, the average COP improved by 0.40 , from 3.51 in 2016 to 3.91 in 2017. In addition, COP values greater than 3.5 were seen more frequently in 2017. Differences were more clearly seen in the system COP whose values fell in the range of 1.0 to 2.0 in 2016 and 1.5 to 2.5 in 2017. The average of the system COP improved by 0.45 , from 1.77 in 2016 to 2.22 in 2017 . Therefore, the watercooled chiller and system COP values were both distributed in higher ranges in 2017 than in 2016.

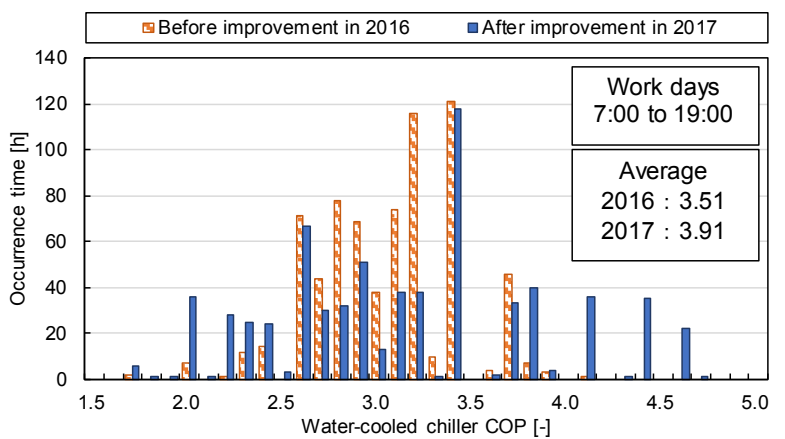

Fig. 4. Occurrence time for water-cooled chiller COP

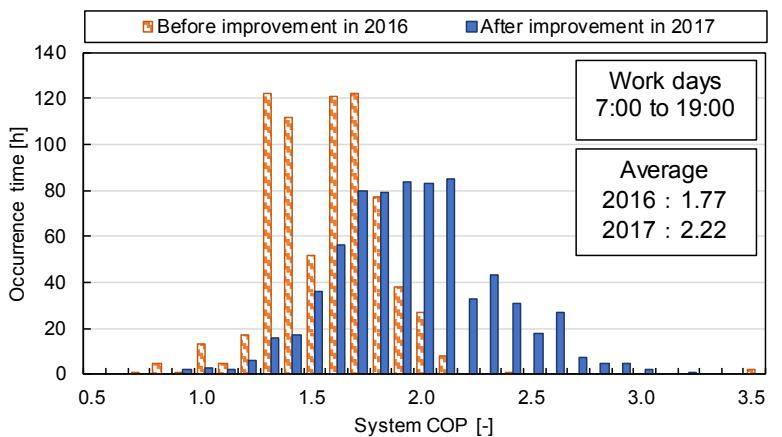

Fig. 5. Occurrence time for system COP
Fig. 6. shows the breakdown of the electric energy consumption and ratio of the pumps and cooling towers compared with the water-cooled chillers. The cooling towers, condenser water pumps, and primary pumps consumed more electricity than the chiller in 2016. After the operation control improvements, the total amount of electric energy consumption was reduced by 12,664 $\mathrm{kWh}$ from the previous year. The main factor for this reduction was the decrease in the energy consumption of the pumps and cooling towers, whose ratio compared to the water-cooled chiller was reduced by $59 \%$. It was confirmed that the heat source was operating more efficiently after the improvements made in 2017.

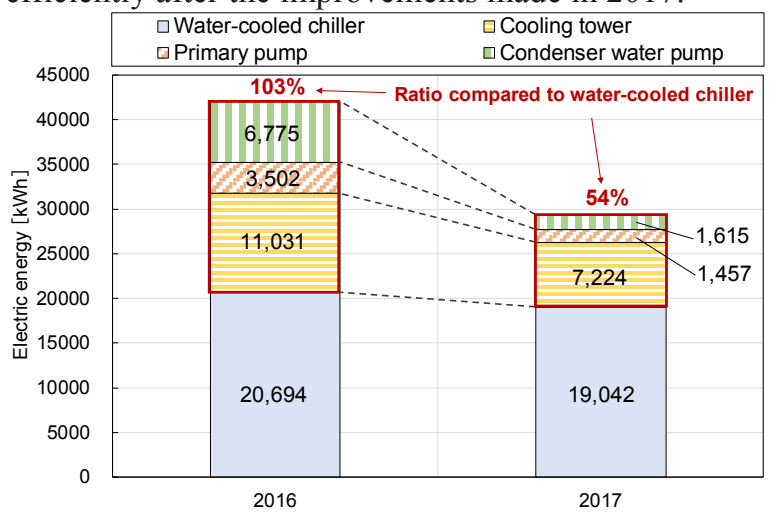

Fig. 6. Breakdown of electric energy consumption and ratio of the pumps and cooling towers compared with the water-cooled chillers

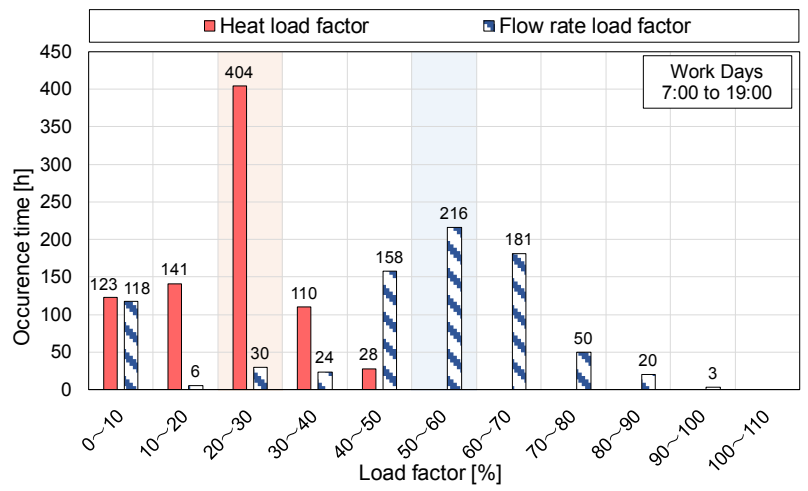

(a) Before improvement (2016)

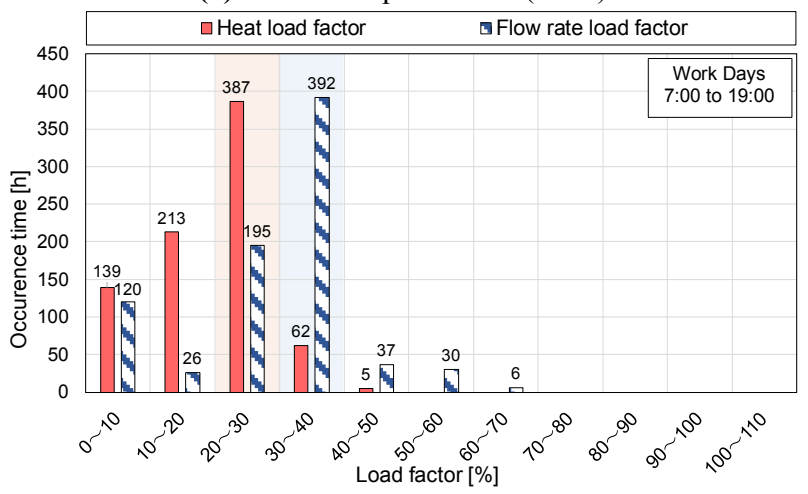

(b) After improvement (2017)

Fig. 7. Heat and flow rate load factors of the water-cooled chillers

\subsubsection{Heat and flow rate load factors}

Fig. 7. shows the heat and flow rate load factors of the water-cooled chillers in 2016 and 2017. The heat load 
factor refers to the ratio of the heat load (in this case the actual heat extracted) and the nominal equipment capacity [4]. Similarly, the flow rate load factor refers to the ratio of the actual water flow rate and the nominal flow rate. Hourly load factors were calculated in the previously mentioned time period. For both years, the peak heat load factor was between $20 \%$ and $30 \%$. On the other hand, the peak flow rate load factor was between $50 \%$ and $60 \%$ in 2016 , and it decreased to between $30 \%$ and $40 \%$ in 2017 . Because the peak for both heat load factors took similar values, it can be said that approximately the same amount of heat load was processed with a lower water flow rate.

\subsection{Air handling units}

Fig. 8. shows the heat and flow rate load factors of the high-temperature cooling coil in 2016 and 2017. The calculation conditions are the same as those mentioned in the previous section. High-temperature cooling coils of the four air handling units on the subjective floor were observed. The peak heat load factor was between $0 \%$ and $10 \%$ in 2016 and between $20 \%$ and $30 \%$ in 2017 . For the flow rate load factor, the peak value decreased from between $90 \%$ and $100 \%$ in 2016 to between $30 \%$ and $40 \%$ in 2017 . As with the heat source, it can be said that the same amount of heat load was processed with a lower water flow rate for the air handling units as well.

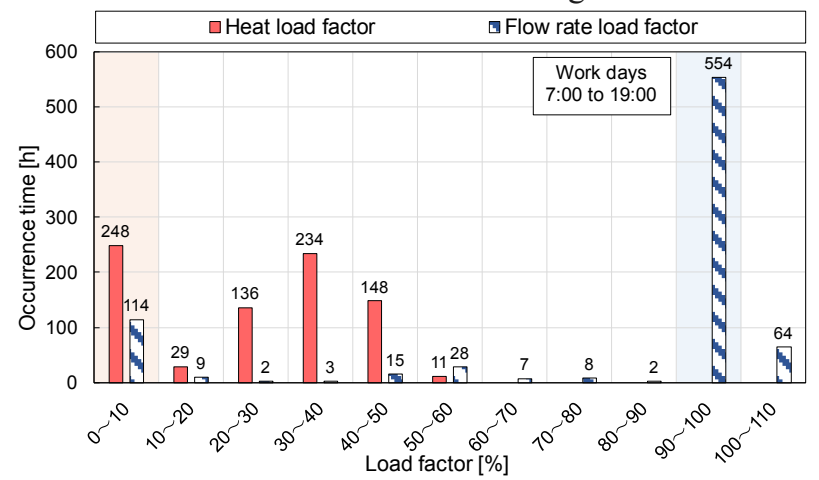

(a) Before improvement (2016)

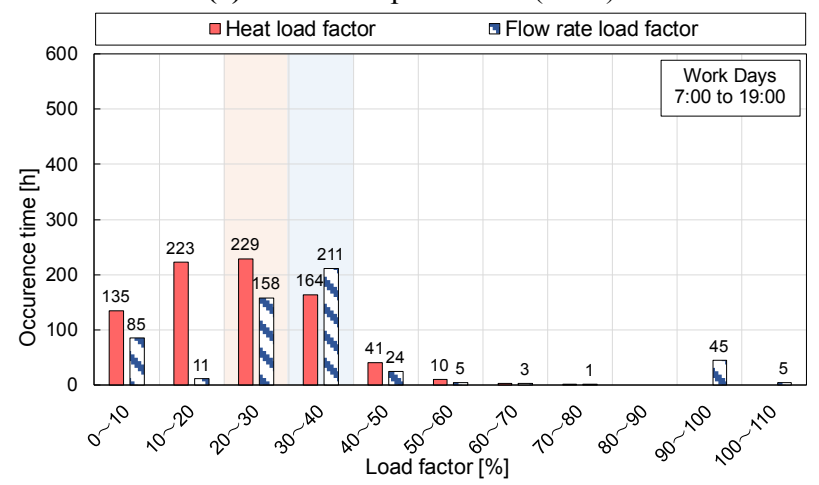

(b) After improvement (2017)

Fig. 8. Heat and flow rate load factors of the high-temperature cooling coil

\section{Conclusions}

In this study, the actual conditions of each component using high-temperature chilled water in an office building were analyzed by the BEMS data in 2016. As a result of the analysis, it was found that there was room for improvement in the operating conditions of each component. Therefore, changes were made to the operation control of the cooling tower, condenser pump, primary pump, secondary pump, and air handling unit in July 2017. The cooling tower was controlled so that the outlet temperature follows the outside air wet-bulb temperature. Condenser water pumps and primary pumps had their inverter frequency lower limit reduced to ensure the temperature difference. Secondary pumps also had their inverter frequency lower limit reduced to lower the delivery pressure. Air handling units using high-temperature chilled water had their valve control adjusted to obtain a constant return water temperature. The efficiency of each component was evaluated before and after operation control improvements. The obtained results are described below:

1) The water-cooled chiller and system COP improved by 0.40 and 0.45 , respectively, after the operation control changes. The total amount of electric energy consumption was reduced by $12,664 \mathrm{kWh}$. In addition, the ratio of energy consumption of the pumps and cooling towers as compared to the watercooled chillers was reduced by $59 \%$.

2) Both the water-cooled chiller and air handling units were able to process the same heat load with a lower water flow rate as compared with the previous year.

Thus, it can be said that the high-temperature cooling equipment operated more efficiently as compared to the year prior to the improvement.

The authors are grateful to all parties concerned for providing careful and considered feedback and valuable comments.

\section{References}

1. D. Hatori, Design and Verification of the Advanced Office Building (Part 1), Summaries of Technical Papers of the Annual Meeting, Society of Heating Air-Conditioning and Sanitary Engineers of Japan, (2015) (In Japanese).

2. Y. Miyashita et al., Development of Desk Built-in Personal Comfort System Installed Cooling and Heating Panel and Task Fan (Part 1), Summaries of Technical Papers of the Annual Meeting, Architectural Institute of Japan, (2015) (In Japanese).

3. Energy Saving Karte, Tokyo Metropolitan Governm ent Bureau of Environment (2015), http://www.kank yo.metro.tokyo.jp/climate/large_scale/data/karte.file s/karte_2_20171213.pdf(In Japanese).

4. H. Masaya, Study on Performance of Multi-Split Type Air-Conditioning System as well as Air Conditioner and Safety Factor for Selection of Equipment, Doctoral dissertation, Nagoya University, 16-107 (2016) (In Japanese). 